\title{
DESAFIOS DE UM CONSTITUCIONALISMO GLOBAL: A SOBREPOSIÇÃO DE ESPAÇOS NORMATIVOS E O ESTADO CONSTITUCIONAL COOPERATIVO
}

\author{
${ }^{1}$ Álvaro de Oliveira Azevedo Neto \\ ${ }^{2}$ Thaís Vandresen
}

\begin{abstract}
RESUMO
O artigo tem por objeto analisar os desafios que se apresentam ao constitucionalismo contemporâneo diante da sobreposição e fragmentação de espaços normativos nas ordens internacional e constitucional. O objetivo é identificar as teorias concernentes ao constitucionalismo global e o constitucionalismo de cooperação que apresentam a relativização do paradigma vestefaliano de Estado. Justifica-se o estudo tendo em vista a fragmentação da esfera pública e a necessidade de se compreender o sistema normativo plural decorrente da aproximação dos marcos regulatórios presentes tanto no Direito Internacional quanto no Constitucionalismo doméstico.
\end{abstract}

Palavras-chave: Globalização, Constitucionalismo global, Constitucionalismo cooperativo

\section{DESAFÍOS DE UN CONSTITUCIONALISMO GLOBAL: LA SUPERPOSICIÓN DE ESPACIOS NORMATIVOS Y EL ESTADO CONSTITUCIONAL COOPERATIVO}

\section{RESUMEN}

El objeto del artículo es analizar los retos que se presentam al constitucionalismo contemporáneo ante la superposición y la fragmentación de espacios normativos en los órdenes constitucionales nacionales y internacionales. El objetivo es identificar a las teorías sobre el constitucionalismo global y el constitucionalismo de cooperación que cuentam con la relativización del paradigma westfaliano de estado. El estudio se justifica en cuanto a la fragmentación de la esfera pública y la necesidad de entender el sistema plural normativo resultante de la aproximación de marco normativo presenta tanto en el derecho internacional y el constitucionalismo nacional.

Palabras-claves: Globalización, Constitucionalismo global, Constitucionalismo cooperativo

\footnotetext{
1 Doutor em Direito pela Universidade Federal de Pernambuco - UFPE, Recife, Brasil. Professor e Coordenador Acadêmico do Curso de Direito da Faculdade Boa Viagem - FBV, Brasil. E-mail: aneto7@fbv.edu.br (Brasil)

2 Doutoranda em Ciência Jurídica na Universidade do Vale do Itajaí - UNIVALI, Santa Catarina, Brasil. Advogada. e Professora junto aos Cursos de Graduação e Especialização em Direito da Universidade do Vale do Itajaí. E-mail: thaisvandre@gmail.com (Brasil)
} 


\section{INTRODUÇÃO}

Como entender a relação entre sistemas normativos plurais que apresentam-se como hierarquicamente superiores uns aos outros em um cenário de fragmentação sistêmica onde a ordem pode indicar a desordem? A sobreposição de competências e a aproximação de esferas normativas faz com que disposições constitucionais entrem em conflito com a agenda internacional, levando a necessidade de se revisitar conceitos clássicos e questionar estruturas reconhecidamente sólidas em processos de fragmentação. O presente ensaio tem como objetivo contra-posicionar duas potenciais soluções para o problema que surge da fragmentação dos espaços das ordens normativas internacional e constitucional: o constitucionalismo global e o constitucionalismo de cooperação.

Neste sentido, através de uma análise bibliográfica de natureza dedutiva, teorias semelhantes são analisadas em correlação ao objeto seu central comum, que seria a visão do constitucionalismo em perspectiva global-internacional.

Para este fim, desenvolve-se o raciocínio em três etapas distintas. Na primeira analisa-se o fenômeno da necessidade de superação do modelo vestefaliano de Estado, que funciona como elemento de contextualização e como ponto comum das ideias que se apresentam em sequência. Mais adiante, trata-se do constitucionalismo e da sua versão global como resultados destes processos de transformação normativa. Ao final apresenta-se o constitucionalismo cooperativo como solução alternativa para o mesmo problema.

Sob uma perspectiva doutrinária, utiliza-se GIDDENS e DAHL para conceitos sociológicos e de matriz democrática, bem como FARIA e CAPELLA para a contextualização da problemática política que leva ao problema presente no Direito. Mais adiante, o marco teórico apresentado busca em MADURO, NEVES, CANOTILHO, SLAUGHTER, BURKE-WHITE e PETERS fundamentos para uma nova matriz constitucional de natureza global. Ao final, utiliza-se a matriz teórica de HABERLE para entender uma solução alternativa, de natureza cooperativa. Outros autores também foram utilizados como complementos para este marco.

\section{Contextualização:}

O termo globalização é utilizado para definir diversos fenômenos deste início de século. Tantos são estes que o vocábulo aparenta ter apreendido diversos significados diferentes, atribuindo carga negativa ou positiva à narrativa da qual 
Álvaro de Oliveira Azevedo Neto \& Thaís Vandresen

participa. Define-se o mesmo, em sua versão mais simples, como uma simples mudança, ou transformação, da escala de organização humana na qual as relações de poder alcançam magnitudes globais. A globalização gera um acréscimo de atividades e redes transfronteiriças, gerando ao mesmo tempo uma necessidade de harmonização (econômica, judicial, política, ambiental...) que poderá progredir em integração entre nações e culturas, como também alimenta animosidades e conflitos (HELD, 2004, pp. $1-6)$.

Pode-se simplificar este dilema definindo este processo de globalização utilizando a teoria de GIDDENS, de matriz teórica estruturalista ${ }^{1}$, que diz: A globalização pode ser definida como a intensificação mundial de relações sociais que liga locais distantes de tal forma que eventos locais são moldados por outros eventos que acontecem a muitas milhas de distância e vice-versa (GIDDENS, 1990, p. 64).

Alguns fatores alimentam os processos de globalização, enquanto outros dependem dela para encontrar alguma solução. A nova estrutura de comunicação e a revolução da tecnologia de informação, os novos mercados globais munidos de distribuição global, o desenvolvimento de novos níveis de processos políticos e a formação de novas instâncias governamentais, a difusão de valores democráticos pósguerra fria, a internacionalização da segurança contra o terrorismo, as pandemias e crises ambientais, os processos migratórios e a emergência de uma nova sociedade global são alguns dos fatores que alavancam o processo globalizante.

Segundo DAHL (1994), a história do Estado moderno e de seu sistema político passa por três grandes mudanças, sendo a primeira a instituição da cidadeestado com seu sistema democrático direto na Grécia antiga e a segunda o surgimento do Estado-nação moderno, dotado de um sistema democrático indireto representativo que lhe é típico. De acordo com esta teoria, a história contemporânea encontra-se na terceira transformação, que inclui novos agentes políticos.

The third transformation, then, is the one now taking place. Just as earlier city-states lost much of their political, economic, social, and cultural autonomy when they were absorbed into larger national states, so in our time the development of transnational systems reduces the political, economic, social, and cultural autonomy of national states. (DAHL, 1994, p. 2).

\footnotetext{
${ }^{1}$ A teoria estruturalista, diferente do estruturalismo, busca identificar a ação social de acordo com sua relação no tempo e no espaço. A estrutura social e sua cultura estariam sujeitas as relações a si submetidas nestas variáveis tempo e espaço, sendo também o resultado da composição da prática coletiva de seus agentes (GIDDENS, 1979, p.2), . Esta teoria tem Anthony Giddens como um de seus principais representantes de seu núcleo teórico paradigmático e é especialmente eficiente quando se busca compreender a ideia de globalização.
} 
Esta conjectura nunca antes vista faz-se cada vez mais presente na realidade jurídica-política do Estado. Ao mesmo tempo que se observa um movimento de independência dos povos e formação de novos Estados pós-1945, observa-se também uma aproximação da política destes Estados, que se vê presente nas mais diversas formas de coordenação multilateral internacional. Pode-se utilizar como exemplo deste processo o sistema institucional gerado pela Organização das Nações Unidas, criada neste mesmo ano de 1945.

\begin{abstract}
Globalism and the networks of interdependence that it reflects create the potential for discord, since the desired actions of governments often adversely affect their neighbors. The simplest solution - to internalize these externalities in larger political units - is rendered difficult, often impossible, by the world's variety of cultural practices and politicaleconomic preferences, difficulties of cross-cultural communication, and competition among ruling elites. World government seems infeasible as a result of this heterogeneity. But national autarchy is highly inefficient, and autonomous action in political anarchy generates conflict. World politics is thus bedeviled by a dilemma of governance: sufficient governance to control conflict and generate economic efficiency has often been unattainable as a result of political and cultural fragmentation. (KEOANE, NYE, 2001, p. 2).
\end{abstract}

Este fenômeno que aproxima unidades políticas distintas aparenta projetar-se em todas as esferas sociais. Contudo, o mesmo torna-se mais evidente nas searas econômica, política e jurídica. As novas unidades de produção, movidas por multinacionais com sistemas produtivos distribuídos em escala global e integrados muitas vezes pelo universo virtual, e sua ligação às estruturas produtivas locais tornam a globalização econômica uma das mais fáceis de se perceber. A emergência de uma nova política global também se faz perceber dentro deste processo, fazendo com que inclusive as instituições sob as quais baseia-se a toda organização social do Estado sintam estes efeitos. Os procedimentos democráticos estão transnacionalizando-se, já que o território do Estado não é mais o seu único alvo. No que tange o Estado, este aparenta perder a sua construção clássica, fato que reflete sobre o seu controle, soberania e sistema jurídico (SHAPIRO, I.; HACKERCORDÓN, C., 1999, pp. 55-57).

A necessidade de se haver legitimidade no poder e na ordem pública é constante na história da humanidade. A variedade de pensamentos é praticamente incalculável, contudo nota-se que este plexo teórico converge para vários pontos e preocupações comuns. Desta convergência vê-se como principal foco de questionamento a origem do poder político e a sua soberania. Desdobram-se duas preocupações: quem é a autoridade legítima e soberana e quais os seus limites de atuação (HELD, D. 1995, p. 39). 
A conclusão óbvia que se chegou até então foi que esta autoridade deveria estar ligada ao consentimento do povo e vinculada às fronteiras da comunidade. Contribuem estes pensamentos para a concepção da democracia como regime representativo, que leva à legitimação do poder dentro da esfera democrática nacional.

O estado é necessário como poder de organização, de sanção e de execução, porque os direitos têm que ser implantados, porque a comunidade de direito necessita de uma jurisdição organizada e de uma força para estabilizar a identidade, e porque a formação da vontade política cria programa que têm que ser implementados (HABERMAS, 2003 (1929), V. 1, p. 171).

O Estado moderno então tornou-se, junto com a democracia representativa, o padrão de poder legítimo, já que a força é consentida pelo povo e dividida pelo governo. Os responsáveis pela política pública têm responsabilidade eleitoral (ou input accountability) por estarem submetidos a um processo de seleção ligado aos cidadãos-eleitores e podem ser responsabilizados por seus atos (output accountability) devido a possibilidade de terem suas ações questionadas pelo mesmo povo que os elegeu (HELD, D. 1991, p. 198).

O poder político modificou sua estrutura de forma profunda com a "grande transformação". Entretanto, pela primeira vez, desde o nascimento da modernidade, não pode este poder político ser descrito em termos de soberania e legitimidade simples. "O campo de poder contemporâneo está constituído pela inter-relação de um soberano privado supra estatal difuso e um "Estado permeável" ou umas "associações estatais" permeáveis, abertas ou porosas" (CAPELLA, 2002, p.255).

Existem quatro grandes rupturas da ordem atual com a anterior, vinculada à concepção moderna de Estado. A primeira é resultado do fim da Guerra Fria e o fim da segurança coletiva bipolar. A existência de um modelo multipolar mais complexo e mais instável faz necessária a formulação de novas alianças internacionais para garantir a segurança e integridade nacional (FARIA, 1996, p. 17).

As noções de colonialismo, imperialismo, dependência e interdependência, assim com as de projeto nacional, via nacional, capitalismo nacional, socialismo nacional e outras, envelhecem, mudam de significado, exigem novas formulações. Na medida que se desfazem as hegemonias construídas durante a Guerra Fria, declinam as superpotências mundiais, envelhecem ou apagam-se as alianças e acomodações estratégicas e táticas sob as quais desenhava-se o mapa do mundo até 1989 , quando caiu o Muro de Berlim, emblema do mundo bipolarizado (IANNI, 1999, p.12). 
A mundialização da economia é a causa da segunda ruptura. "O desenvolvimento das forças econômicas a um nível planetário diminui o poder de coação dos Estados Nacionais sobre elas” (FARIA, 1996, p. 18). Uma polícia social, tal como aquela do segundo modelo de Estado moderno está fadada ao fracasso, já que uma política social em um só país torna-se ineficaz quando, devido a um intercâmbio e uma internacionalização de firmas como no momento atual, a pressão estatal gera apenas o deslocamento de uma empresa deste para outro Estado Nacional.

\begin{abstract}
A nova divisão transnacional do trabalho envolve a redistribuição das empresas, corporações e conglomerados por todo o mundo. (...) a nova divisão transnacional do trabalho e produção implica outras e novas formas de organização social e técnica do trabalho, de mobilização da força de trabalho, quando se combinam trabalhadores de distintas categorias e especialidades, de modo a formar-se o trabalhador coletivo desterritorializado (IANNI, 1999, p.13-14).
\end{abstract}

A terceira ruptura vem com a necessidade de uma gestão global de vários problemas, tornando necessária a confecção de organismos e organizações internacionais, que obrigam os Estados a coordenar suas políticas, já que os organismos internacionais por eles mesmos criados influirão nos seus processos políticos internos (FARIA, 1996, p. 19).

A quarta ruptura vem com a instituição do Direito Internacional como, cada vez mais, um princípio normativo superior, fato o qual comprova-se com a grande quantidade de acordos e tratados de cooperação e integração econômica, que chegam a possibilitar a ação de um indivíduo contra um Estado dentro de uma corte internacional (como o Tribunal Europeu de Justiça).

(...) verifica-se o declínio do Estado-nação. Parece reduzir-se o significado da soberania nacional, já que o Estado-nação começa a ser obrigado a compartilhar ou aceitar decisões e diretrizes provenientes de centros de poder regionais e mundiais. (...) Se por um lado o Estado-nação é levado a limitar e orientar os espaços da cidadania, por outro lado, as estruturas globais de poder são levadas a limitar e orientar os espaços da soberania nacional (IANNI, 1999, p. 16)

O Estado encontra-se, então, numa grande crise de legitimidade, já que todas as rupturas acima elencadas terminam por causar uma grande perda da soberania e autonomia dos Estados Nacionais em suas políticas internas. Pode-se concluir, desta primeira etapa, o mesmo que Ives Gandra Martins: “... o Estado Moderno está, em sua formulação clássica de soberania absoluta, falido, devendo ceder campo a um Estado diferente, no futuro" (MARTINS, 1998, p. 19). 
A crise que é determinada pela revolução das comunicações reflete-se na economia, na política e o direito, e em todas as dimensões da vida social, inverteu as velhas fronteiras de estado, gerando problemas dramáticos que se mantêm irrevogavelmente acima dele: como o retorno da guerra como meio de solução das controvérsias entre Estados. (...) uma terceira mudança, com a formação os Estados nacionais é aquela que se têm realizado sucessivamente com o seu reestruturamento de acordo com o paradigma da democracia constitucional (FERRAJOLI, 2007, p. 483). ${ }^{2}$

Esta transformação, ou mudança de fase, indica uma forma diferente de interação global daquela clássica estudada outrora.

O Estado começará a aparecer como um fator de opacidade e de 'ruído' para uma ideologia da 'transparência' comunicacional, que se relaciona estritamente da comercialização dos saberes. É sob este ângulo que se arrisca apresentar-se com uma nova acuidade o problema das relações entre as instâncias econômicas e as instâncias estatais (LYOTARD, 1993, p. 06).

Segundo JESSOP (2006), trabalhos recentes acerca da globalização tem feito surgir dúvidas quanto ao futuro do Estado moderno, de configuração territorial soberana, devido ao surgimento de novas fontes normativas supranacionais e transnacionais. Este fato é apoiado pela mudança de escala na política econômica global. Diz ele que enquanto o Estado era o principal fornecedor de organização política na era de Ford (do pós segunda guerra mundial), hoje já se pode observar esta manifestação de poder soberano em outras fontes não estatais, que buscam assegurar a segurança ação coletiva através de normas oriundas de novas escalas políticas, mais capazes de lidar com estes novos processos. Em suas palavras: "Isto [o problema de

\footnotetext{
${ }^{2}$ Tradução livre do autor. Originalmente: La crisi è determinata dalla rivoluzione in atto nelle comunicazioni, nell'economia, nella politica e nel diritto, che di tutte queste dimensioni della vita sociale ha travolto i vecchi confini statali, generando problemi drammatici ormai irreversibilmente sovrastatali: dal ritorno della guerra quale strumento di soluzione delle controversie tra Stati. (...) un terzo mutamento, dopo il primi due avvenuti con la formazione degli Stati nazionali e quello successivamente compiutosi con 1 a loro rifondazione secondo il paradigma della democrazia constitutionale.
}

ação coletiva em novas escalas] faz com que desenvolva interesse na União Europeia como uma nova forma de Estado, como o ressurgimento do poder de império em princípio ordenador, como perspectiva de um Estado global.” , (JESSOP, 2006, pp. $126-127)$.

The crisis of domestic sovereignty is paralleled by the collapse of the image of the international world as a single, hierarchical structure at the 
top of which the United Nations governs a world of tamed sovereigns through public law and diplomacy. The new global configuration builds on informal relationships between different types of units and actors while the role of the state has been transformed from legislator to a facilitator of self-regulating systems. (Koskenniemi e Leino, 2002, p. 557).

\section{O ESTADO CONSTITUCIONAL GLOBAL E A INTERNACIONALIZAÇÃO DOS SISTEMAS NORMATIVOS DOMÉSTICOS}

Há uma clara disputa de espaço normativo entre ordens jurídicas internacional e constitucional, o que significa que a internacionalização do sistema político vem afetando a forma através da qual se atualiza o Direito Constitucional. SLAUGHTER e WHITE (2007) entendem que a tradição formal Vestefaliana traz o desejo de isolamento do Estado soberano e que a natureza dos problemas internacionais demandam uma mudança na estrutura normativa. Como descrito por PETERS (2009), as constituições dos estados vem aumentando gradualmente as referências ao Direito Internacional e as suas disposições regulatórias tem origem interestatais. Isto posto, entende-se que o debate político internacional vem ganhando espaço dentro do espaço até então exclusivamente doméstico. Esta realidade também é mencionada por NEVES (2013), como se demonstra abaixo:

A diminuição da capacidade regulatória do Estado com a emergência de novos problemas globais relaciona-se, paradoxalmente, com o incremento das tarefas que se apresentam ao Estado em face dos novos desafios da sociedade mundial. (...) o que tem ocorrido é o entrelaçamento das ordens estatais internacionais, supranacionais, transnacionais e locais no âmbito do sistema jurídico mundial de níveis múltiplos, a partir do qual se tem desenvolvido o transconstitucionalismo da sociedade mundial (NEVES, 2009, p. 189).

O referido dilema atinge também as instâncias judiciais. A globalização judicial (SLAUGHTER, 2000), que faz com que exista uma interação através das fronteiras estatais, faz com que tribunais troquem ideias e cooperem em casos não apenas internacionais como também em processos judiciais de Direito doméstico.

Entende-se que uma das consequências da internacionalização do sistema constitucional é o seu efeito diminuidor dos poderes políticos do estado. Processos que ocorrem em decorrência da interferência da esfera internacional sobre a estrutura doméstica geram a transferência dos debates políticos para as instituições internacionais, onde as esferas de governo e de governança se confundem. 
A necessidade de regular e orientar o comércio, por exemplo, faz com que os estados criem organizações especializadas e transfiram para estas a responsabilidade política. Isto tem um efeito direto a longo prazo sobre a sua soberania, que é gradualmente erodida para estas instituições internacionais, que em seu caminho criam um ambiente internacional juridicamente plural. Marcelo Neves defende a existência de uma governança multilateral, resultante dessa mudança, que por sua vez necessita harmonizar as legislações e práticas jurídicas, como acontece no âmbito de fóruns e agências internacionais de direitos humanos. Como resultado, a sociedade global gradualmente cria um paradigma constitucional de natureza trans.

Interações entre os sistemas nacionais e internacionais podem ser resolvidas, como a Escola de Viena propôs, através de um sistema de visão singular. Isto significa que um dilema de hierarquia seria criado posteriormente, de forma a determinar qual o conjunto de regras é superior ao outro. Por outro lado, uma abordagem dual (ou plural) parece ser mais pertinente. Direito constitucional Universal é pouco provável que venha a existir a curto prazo, devido à natureza inorgânica da atual fragmentação da sociedade universal em um número de comunidades políticas separadas. A estrutura inorgânica de direito internacional geral, a natureza inorgânica da sua formação normativa, sua forma particular e seus processos de aplicação do direito da sociedade internacional buscam estabelecer regras jurídicas internacionais em um sentido amplo. Isso força os sistemas a darem uma volta em torno de si e interagir em sua própria maneira particular. Essa interação contínua de ambos os sistemas internacionais e nacionais tem feito com que a norma doméstica passe a incorporar a agenda internacional através de tratados ou princípios constitucionais não escritas (ou legislação $a d$ hoc).

Esta fragmentação da esfera pública, que gera governanças multilaterais, aparenta ser a próxima tendência na política global. SLAUGHTER (1997) definiu esta tendência como a Verdadeira Nova Ordem Global (The Real New World Order), ao final da década de noventa, quando as redes de cooperação buscavam maior legitimidade política. Existe ordem nesta disordem, mas esta é plural e busca maior legitimidade e mecanismos de accountability.

Judges are building a global community of law. They share values and interests based on their belief in the law as distinct but not divorced from politics and their view of themselves as professionals who must be insulated from direct political influence. At its best, this global community reminds each participant that his or her professional performance is being 
monitored arid supported by a larger audience. National and international judges are networking, becoming increasingly aware of one another and of their stake in a common enterprise. The most informal level of transnational judicial contact is knowledge of foreign and international judicial decisions and a corresponding willingness to cite them. (SLAUGHTER, 1997, p. 186).

PETERS definiu como constitucionalismo global o surgimento de elementos constitucionais na ordem jurídica internacional. Mesmo que não há constituição internacional, existem valores que são criados através do processo de fertilização cruzada descrito acima.

'Constitutionalization' is shorthand for the emergence of constitutional law within a given legal order. The concept of constitutionalization implies that a constitution (or constitutional law) can come into being in a process extended through time. It also implies that a legal text (or various legal texts) can acquire (or eventually lose) constitutional properties in a positive feedback process. A text can therefore be more (or less) constitution-like. It may be, in short, a constitution-in-themaking. In consequence, 'global (or international) constitutionalization' is used in this paper as a catchword for the continuing process of the emergence, creation, and identification of constitution-like elements in the international legal order (PETERS, 2006, p.4)

Isto posto, nesta nova estrutura proposta, governos e jurisdições ajustam o exercício de sua função soberana do Estado, que passa a atuar conforme esta nova realidade. Portanto, esta nova estratégia não deve ser vista como um processo de erosão soberana, mas como a resposta à nova ordem internacional que se apresenta.

A doutrina constitucional nacional e internacional busca trazer conceitos que expressam estas ideias. Ideias como o interconstitucionalismo (CANOTILHO, 2008), transconstitucionalismo (NEVES, 2009), constitucionalismo transnacional (TSAGOURIAS, 2007), constitucionalismo plural (MADURO, 2006), e outras aparentemente sugerem a aplicação do bloco de constitucionalidade, correspondendo a ideia do constitucionalismo internacional de PETERS (2006).

A ideia de um constitucionalismo global remete-se ao fato de que o Estado-Nação, como anteriormente concebido no exercício de sua soberania, não consegue responder à demanda do estado administrativo e sua interação com a sociedade civil e a economia capitalista global. Essa relação passa a ser mediada com base na integração entre Estados (organizações internacionais; instrumentos multilaterais; comunidades integradas). O Estado Constitucional Moderno não apenas se relaciona política, econômica e socialmente com outros Estados, mas se submete ao controle de organismos externos transferindo a estes poderes e competência jurisdicional. 
Nesse sentido é a crítica que CANOTILHO (2009, 109-110) estabelece dos textos constitucionais dirigentes ainda enclausurados no seu "autismo nacionalista e patriótico". Observa o autor que as pré-condições constitucionais da política se situam fora do espaço nacional e estatal, superando o dogma do "Estado-soberano" e de "soberania constitucional", ou seja, mesmo que as constituições continuem a representar a "magna carta da identidade nacional", sua força normativa terá que ceder "perante novos fenótipos político-organizatórios, e adequar-se, no plano político e no plano normativo, aos esquemas regulatórios das novas associações abertas de estados nacionais abertos".

É nesse contexto, portanto, que PETERS (2009 p. 397) trata do constitucionalismo global (ou internacional) como uma pauta jurídico-política e acadêmica focada em identificar e defender a aplicação de princípios naturalmente de foco constitucional na esfera jurídica internacional.

De acordo com CANOTILHO (2009, p. 283) as vicissitudes do constitucionalismo exigem a atualização dos sistemas normativos domésticos e do paradigma legislativo constitucionalmente estruturante, tendo como ponto de partida as seguintes rupturas paradigmáticas: 1) a superação do referencial ConstituiçãoEstado; 2) a compreensão de um constitucionalismo em constante evolução "constitucionalismo evolutivo" e 3) a substituição do sistema hierárquico por um sistema de governança constitucional.

Do ponto de vista do direito europeu a proposta de CANOTILHO (2009, p. 265-266) é o da formação de uma "teoria da interconstitucionalidade, que estuda as relações interconstitucionais de concorrência, convergência, justaposição e conflitos de várias constituições e de vários poderes constituintes no mesmo espaço político".

Já para NEVES (2013, p. 295), a constituição apresenta-se como a instância e critério básico de compreensão da ordem jurídica estatal e por consequência núcleo inviolável. Não obstante, a teoria propõe o reconhecimento de que diversas ordens jurídicas podem e devem dialogar para a solução de um problema constitucional comum.

A principal causa desta modificação da compreensão do Estado Constitucional contemporâneo vem do novo contexto internacionalizado do Estado, fazendo com que conquistas no jus cogens internacional também passem a fazer parte do acquis constitucional dos Estados (CANOTILHO, 2008, p. 27). MELLO (2000, p. 9), argumenta utilizando como base HESSE, que não existe questão constitucional que 
argumenta utilizando como base HESSE, que não existe questão constitucional que não seja política, da mesma forma que não existiria questão mais política que aquela das relações internacionais dos Estados, tendo em vista que esta pode significar a própria sobrevivência dos Estados no sistema. Neste contexto inicia-se o discurso da função do Direito Internacional Público como complementar a do Direito Constitucional (ou não). Tal como o Direito Constitucional, o Direito Internacional pode acompanhar, mas não substituir, a formação de um espaço político (ABDULNOUR, p. 1278).

Building on this transnational consensus, I employ the term 'global (or inter- national) constitutionalism' in order to characterize a strand of thought (an outlook or perspective) and a political agenda which advocate the application of constitutional principles, such as the rule of law, checks and balances, human rights protection, and democracy, in the international legal sphere in order to improve the effectivity and the fairness of the international legal order (PETERS, 2006, p.5).

VIDMAR (2012) entende que seria necessário criar-se ou revelar-se este sistema internacional de valores, que justifique a existência deste sistema, o que é improvável. Contudo, a evolução do sistema Nações Unidas pode refletir este sistema de valores necessário para se criar uma politeia constitucional (2012, p.5). Assim, chegar-se-ia à coesão necessária para este sistema, já que sua carta traz textualmente estas vontades compartilhadas e obrigações universais.

Tratando do chamado constitucionalismo internacional, (PETERS 2006) posiciona-se dizendo que apesar de não existir norma constitucional internacional, existem normas fundamentais na ordem internacional que por sua vez podem preencher a função constitucional que aqui se busca. Neste sentido, a autora alerta para o fato de que os Estados não conseguem mais fazer "constituições absolutas", devendo deixar espaço para regras internacionais de natureza constitucional. Assim, conclui a autora que para ter a total proteção constitucional é necessária a proteção nos vários níves de governança (governance levels). O problema apontado estaria na governança global e sua falta de legitimidade para esta função.

'Constitutionalization' is shorthand for the emergence of constitutional law within a given legal order. The concept of constitutionalization implies that a constitution (or constitutional law) can come into being in a process extended through time. It also implies that a legal text (or various legal texts) can acquire (or eventually lose) constitutional properties in a positive feedback process. A text can therefore be more (or less) constitution-like. It may be, in short, a constitution-in-themaking. In consequence, 'global (or international) constitutionalization' is used in this paper as a catchword for the continuing process of the 
emergence, creation, and identification of constitution-like elements in the international legal order (PETERS, 2006, p. 4).

Evidente a constatação que entrechoque de ordens normativas diversas no plano global é consequência e efeito da globalização, como já analisado anteriormente, bem como que a ascensão do direito internacional revelou a insuficiência teóricas do paradigma jurídico constitucional que se apresente insensível às contingências e demandas de processos políticos, sociais e jurídicos que ultrapassam as fronteiras do Estado-nação.

Entretanto, as propostas teóricas concernentes ao um constitucionalismo como exigência normativo-funcional em escala global enfrenta diversos obstáculos, tais como: a assimetria política entre os Estados e os processos de colonização do direito por outros sistemas sociais (política e economia). Apesar de todas essas dificuldades e mesmo que atualmente possa parecer inviável essa perspectiva, a discussão acerca da possibilidade de um constitucionalismo global ainda se faz pertinente.

\section{O ESTADO CONSTITUCIONAL COOPERATIVO}

Em 1964 definiu RIKER (in FILIPPOV, ORDESHOOK e SHVETOSOVA, 2004, pp. 1-5) que o federalismo seria a melhor alternativa ao império como técnica de se agregar vastas áreas geográficas sob um governo, devendo: ter ao menos dois níveis de governo para a mesma área ou povo; onde cada nível é autônomo em ao menos uma área de ação; e que exista alguma garantia constitucional desta autonomia nesta área de atuação. Contudo, uma definição mais atual do que seria um sistema federalista poderia simplesmente limitar-se a existência de uma estrutura governamental em múltiplos níveis onde em cada nível existe uma relação direta (eleitoral) ou indireta (por delegação) de legitimidade democrática e há uma base geográfica para a composição dos seus membros.

Neste sentido, utiliza-se a ideia do sistema federal quando se trata dos processos de compartilhamento de poderes em cenário internacional. Por exemplo, logo após o início da vigência do Tratado de Maastricht e antes do Tratado de Lisboa (quando ainda se falava em pilares do templo de Masstricht) poder-se-ia defender a tese de que a União Europeia seria uma forma de confederação com elementos embrionários de federação, como afirma WATT abaixo: 
For instance, the European Union, which in its current form represents a highly developed economic confederation, incorporating even some of the institutional features of a federation, is only embryonic in the development of its two other pillars relating to non-economic aspects, such as foreign and security policy, and justice and home affairs. It is clear that the EU represents just one variant and is not the only possible confederal arrangement. (WATT, 2000, p.155).

Ao incorporar cada vez mais traços de federação, WATT também determina que esta forma híbrida entre confederação e federação resulta do fato de que a opção política está centrada na busca de soluções práticas e não na pureza teórica. $O$ resultado é uma descentralização constitucional assimétrica, utilizada para melhorar a governação e conciliar diferenças políticas nas unidades constituintes.

Um pacto federativo internacional, bem como uma ordem constitucional internacional, parecem ser problemas que ultrapassam a estrutura normativa do Direito Constitucional. KELSEN (apud FASSBENDER, 2007), na década de 20, reconhecia que o Direito Internacional estava limitado pelas estruturas soberanas do Estado. FRIEDMAN (apud FASSBENDER, 2007), chegou a mesma conclusão na década de 60. Solucionando este dilema, utilizando a teoria do Direito, FRIEDMAN indica que os desdobramentos constitucionais internacionais resultam do uso da linguagem do Direito Constitucional dentro do Direito Internacional, sendo o Direito Constitucional da Comunidade Internacional (2007, p. 308) parte do Direito Internacional.

HÄBERLE (2007), apresenta uma construção semelhante a esta. Neste sentido, "o Estado Constitucional Cooperativo" indica pré-formas de estruturas federais, processo, competências e tarefas $(2007$, p. 9). Ainda informa o autor que um Estado Federal mundial é uma realidade de características utópicas, com as quais não se pode confundir o proposto na estrutura de cooperação. Este Estado deve dar continuidade aos processos cooperativos internacionais, pois "Estados Constitucionais e Direito Internacional ou relações internacionais influenciam-se hoje, também, mutuamente, em suas mudanças" (2007, p.10), questionando a separação das duas esferas e determinando que os dois são simultaneamente objeto e sujeito de modificações. Mais adiante, complementa: “Os cruzamentos e as ações recíprocas são por demais intensivas para que se dê a esta forma externa de complementariedade uma ideia exata" (2007, p.12). O exemplo fornecido, também aplicável no sistema brasileiro, é o do Direito internacional para-constitucional, encontrado em tratados internacionais sobre Direitos Humanos. 
Esta cooperação, segundo o autor, transita de formas frouxas a formas mais densas, do soft-law à produção de tratados vinculantes. HÄBERLE ainda recomenda a abertura através de seis mecanismos constitucionais: 1) do reconhecimento à abertura global e à solidariedade; 2) da criação de formas específicas de cooperação; 3) de declarações gerais e universais de direitos fundamentais; 4) de determinaçõos específicas dos efeitos externos das declarações de direitos fundamentais; 5) da gradual inclusão do direito internacional (tratados internacionais com hierarquia constitucional); 6) da tematização de tarefas comunitárias (2007, pp. 14-15).

É reconhecida a tendência a abertura e coexistência entre sistemas constitucional e internacional em diversos Estados modernos contemporâneos, das quais diversas técnicas podem ser utilizadas. Utilizando a relação entre a constituição de Estados soberanos e a construção normativa da União Europeia como exemplo, pode-se desenhar quatro modelos de delegação de poderes para acomodar os seus interesses de integração. Estes modelos iniciais tomaram como base as constituições dos membros que precederam os últimos alargamentos. O primeiro modelo, que abarca as constituições da Alemanha, França, Áustria e Portugal, delega competências diretamente à União Europeia, com cláusulas específicas a este respeito. O segundo, composto pelas constituições da Irlanda, Suécia e Grécia, também delegam poderes diretamente a União Europeia, entretanto têm outras provisões limitando estas delegações. O terceiro modelo acomodou a União Europeia sob uma cláusula acerca de instituições internacionais, onde algumas emendas foram feitas para incorporar alguns aspectos específicos da União, que é o caso da Finlândia, Bélgica, Espanha e Itália. Por fim, o quarto modelo não inclui explicitamente a União Européia em sua constituição, mas simplesmente faz referência à delegação de poderes para instituições internacionais (onde incluir-se-ia a UE), que é o caso de Luxemburgo, Dinamarca e Holanda (ALBI, 2005, p.10).

HÄBERLE (2007) ainda esboça uma tipologia após a análise de diversas modificações e inclusões textuais constitucionais atuais, trazendo como principais desenvolvimentos da técnica constitucional que indica um posicionamento cooperativo: 1) o reconhecimento preambular da família de povos; 2) reconhecimento da tarefa de cooperação (mesmo que regional); 3) artigo de solidariedade ou parceria internacional; 4) recepção de pactos de direitos humanos regionais e ou universais; 5) integração de normas de direito internacional universalmente reconhecidas; 6) artigo que indica primazia do direito internacional em caso de colisões, por exemplo, em Direitos Humanos; 7) normas hermenêuticas que favoreçam a interpretação do Direito 
Internacional; 8) abertura das fontes ao Direito Internacional; e 9) abertura das fontes ao Direito estrangeiro (pp. 57-58) .

Entende-se que HÄBERLE apresenta uma forma de relativização ao isolamento vestefaliano sem, contudo, substituí-lo como se entende na versão de um constitucionalismo global. A ideia de um constitucionalismo de cooperação apresenta um Estado constitucional aberto e com texto permeável, onde existe um potencial constitucional ativo de realização internacional de tarefas conjuntas (2007, p. 70).

\section{CONCLUSÃO?}

Conforme desenhou-se ao longo desta narrativa, entende-se que o globalismo é uma realidade presente e bastante discutida na doutrina desde o final do século XX. A agenda internacional nunca esteve tão presente na agenda doméstica e os problemas internacionais nunca foram tão evidentes. Neste sentido, entende-se que a superação do modelo vestefaliano de Estado ocorrera, trazendo a necessidade da compreensão de novas versões de Estado e de Constituição. FARIA (1996) e CAPELA (2002) descrevem bem este processo, enquanto diversos outros, como NEVES (2009), MADURO (2006), CANOTILHO (2009) e TSAGOURIAS (2007) traduzem suas versões do padrão constitucional que acompanha esta relação.

Apesar de semelhantes, duas visões são apresentadas em paralelo: o constitucionalismo global e o constitucionalismo de cooperação. É interessante se perceber que as duas ideias tem como ponto de partida a fragmentação da esfera pública e a necessidade de se compreender o sistema normativo plural decorrente da aproximação dos marcos regulatórios presentes no Direito internacional e no Constitucionalismo doméstico. De um lado apresenta-se a criação de um sistema de Direito Internacional com linguagem constitucional, capaz de resolver este dilema. Do outro, uma nova visão constitucional cooperativa, onde o Direito Constitucional nacional é responsável não pela integração de sistemas, mas pela cooperação entre ordens. Enquanto o primeiro tem as vantagens da funcionalidade, o segundo tem consigo uma roupagem de viabilidade frente a sua maior preservação da esfera soberana dos Estados.

O que se pode concluir é que este debate fortalece o constitucionalismo contemporâneo colocando em pauta a necessidade de se buscar soluções para a fragmentação sistémica decorrente da aproximação de ordens e sobreposição de competências constitucionais e internacionais. 


\section{REFERÊNCIAS}

ABDUL NOUR, S. D. Teorias em relações internacionais e direito internacional público. RDCI, 52/271 jul-set 2005.

ALBI, A. EU Enlargement and the Constitutions of Central and Eastern Europe. Cambridge University Press, Cambridge: 2005.

ALBI, A. Supremacy of EC Law in New Member States. European Constitutional Law Review, 3: 25-67, 2007.

CANOTILHO, J.J.G., Direito Constitucional e Teoria da Constituição. $7^{\mathrm{a}}$ Edição. Lisboa, Almedina, 2011.

CANOTILHO, J.J.G., Brancosos e Internconstitucionalidade: Itinerários dos Discursos sobre a Historicidade Constitucional. $2^{\text {a }}$ Edição. Lisboa, Almedina, 2008

CAPELLA, J. R. O fruto proibido: uma aproximação hisótico-teórica a teórica ao estudo do direito e do estado. Porto Alegre: Livraria do Advogado, 2002.

COSTELlOE, D. Political Constructivism and Reasoning About Peremptory Norms of International Law. 4 Wash. U. Jur. Rev. 1 (2011).

FARIA, J.E. (Org.). Direito e globalização econômica. São Paulo: Malheiros, 1996.

FASSBENDER, B. The meaning of international constitutional law. In TSAGOURIAS, N. Ed. Transnational Constitutionalism: International and European Perspectives. Glasgow: University of Glasgow, 2007.

FILIPPOV, M., ORDESHOOK, P.C., SHVETSOVA, O. Designing Federalism: a theory of self-sustainable federal institutions. Cambridge University Press: 2004.

GIDDENS, Anthony. Sociologia. Trad. Sandra Regina Netz. 4 ed. Porto Alegre: Artmed, 2005. Título original: Sociology

GOMES, L.F. e MAZZUOLI. V.O., Direito Supraconstitucional. Do absolutismo ao Estado Constitucional e Humanista de Direito. Revista dos Tribunais, São Paulo, 2010.

HÄBERLE, P. El Estado Constitucional. Universidad Autônoma de México, México: 2003. 
HÄBERLE, P. O Estado Constitucional Cooperativo. Rio de Janeiro: Renovar, 2007.

HALE, T; HELD, D. Handbook of Transnational Governance: institutions and inovations. Cambrigde, Polity Press, 2011.

HELD, D. Democracy and the Global Order: From the Modern State to the Cosmopolitan Governance. Londres: Stanford University Press, 1995.

HELD, D, et. al. Global Transformations : politics, economics and culture. Londres : Stanford University Press, 1999.

JESSOP, B. State and State Building. In GODIN, R. et. al. (org) The Oxford Handbook of Political Institutions. (Pp. 111 - 130). Oxford: Oxford University Press, 2006

KEOHANE, R; NYE Jr, J. Democracy, Accountability and Global Governance. 2001.

KEOHANE, R; NYE Jr, J. The Club Model of Multilateral Cooperation and Problems of Democratic Legitimacy. 2000.

KOSKENNIEMI, M. From Apology to Utopia. Cambridge, Cambridge: 2005.

KOSKENNIEMI, M. The politics of international Law. Cambridge, Cambridge: 2011.

MADURO, M. P. A Constituição Plural: constitucionalismo e União Europeia. Estoril, Principia: 2006.

MILANOVIC, M. Norm conflict in international law: whiter human rights? Duke J. Comp. \& Int'1 L. 69, 2009.

NARDIN, T. International pluralism and the rule of law. Review of International Studies (2000), 26, 95-110.

NEVES, M. Transconstitucionalismo, São Paulo, Martins Fontes: 2009.

NITEO-NAVIA, R. International Peremptory Norms (Jus Cogens) and International Humanitarian Law. 2012. Disponível em: 
[http://www.iccnow.org/documents/WritingColombiaEng.pdf] acesso em 30 de 07 de 2014.

OLIVIEIRO, M.; CRUZ, P. M. C.. Fundamentos de direito transnacional. In: ROSA, A. M. da; STAFFEN, M. R. (Orgs). Direito Global: transnacionalidade e globalização jurídica. [recurso eletrônico]. Itajaí: UNIVALI, 2013

PETERS, A. Humanity as the A and $\Omega$ of Sovereignty. The European Journal of International Law, 2009.

PETERS, A. The Merits of Global Constitutionalism. Indiana Journal of Global Legal Studies: Vol. 16: Iss. 2, Article 2, 2009. Disponível em: http://www.repository.law.indiana.edu/ijgls/vol16/iss2/2. Acesso em 16 de fevereiro de 2015.

PETERS, A., Compensatory Constitutionalism: The Function and Potential of Fundamental International Norms and Structures (January 1, 2006). Leiden Journal of International Law, Vol. 19, pp. 579-610, 2006. Acesso em: 01/12/2015. Disponível em: http://ssrn.com/abstract=1564125.

PICCIOTTO, S. Constitutionalizing multilevel governance?, I•CON, Volume 6 , Number 3 \& 4, 2008.

ROSENFELD, M. Rethinking constitutional ordering in an era of legal and ideological pluralism $\mathrm{I} \cdot \mathrm{CON}$, Volume 6, Number 3 \& 4, 2008, pp. 415-455

SANDS, P. Treaty, Custom and the Cross-fertilization of International Law. Yale Rights and Development Law Journal. Vol. 1. 1999.

SILVA, E. D., Tratados Internacionais e Lei Interna no Brasil. 2003, Revista Tributária e de Finanças Públicas no. 49/9.

SLAUGHTER, A.-M., The Real New World Order, 76 FOREIGN AFF. 183, 186 (1997)

SLAUGHTER, A.-M Typology of Transjudicial Communication. 29 U. Rich. L. Rev. 99: 1994-1995

SLAUGHTER, A-M. Judicial Globalization. Virginia Journal of International Law. Charlottesville, v. 40, p. 1103-1124, 2000. Disponível em: http://www.princeton. edu/ slaughtr/Articles/VJIL.pdf. 
SLAUGHTER, A.-M.. A New World Order: Government Networks and the Disaggregated State. Princeton: Princeton University Press, 2004.

SLAUGHTER, A-M e BURKE-WHITE, W. The Future of International Law is Domestic (or, the European Way of Law). in Janne E. Nijman and André Nollkaemper, New Perspectives on the Divide Between National and International Law. (Oxford: Oxford University Press. 2007)

TAVARES, A. R. et.al. Estado Constitucional e organização do poder. São Paulo: Saraiva: 2010.

TEUBNER, Gunther. Constitutionalising polycontexturality. Social and Legal Studies. London, n.19, 2010. Disponível em: http://www.jura.unifrankfurt.de/42852930/constitutionalisingpolycontexturality_eng.pdf. Acesso em 24 de fevereiro de 2015, p. 1

TSAGOURIAS, N. Ed. Transnational Constitutionalism: International and European Perspectives. Glasgow: University of Glasgow, 2007.

VALADÉS, D. In HABERLE. prefácio a El Estado Constitucional europeo. Haberle. Livro eletrônico disponível em: [http://www.bibliojuridica.org/libros/libro.htm?l=14] 2003, P. XXVIII

VIDMAR, J. Norm Conflicts and Hierarchy in International Law: Towards a Vertical International Legal System? Oxford: OUP, 2012.

WATT, R. L. States, Provinces, Länder, and Cantons: International Variety among Subnational Constitutions, 31 Rutgers L.J.: 2000 p. 941, 942

ZAGREBElSKY, G. El Derecho Dúctil: ley, derechos, justicia.10 ${ }^{\mathrm{a}}$ Ed., Madrid, Editorial Trotta, 2011

ZENOVIC, P. Human Rights Enforcement via Peremptory norms: a challenge to state sovereignty. RGSL Research Papers, Riga: 2012. 